\title{
Sexual and Reproductive Health: Layers of (in)Access
}

\author{
Xanthe Hunt, Leslie Swartz, Stine Hellum Braathen, \\ and Poul Robleder
}

\section{INTRODUCTION}

Access has three layers.

Here are the first two: (1) Is there something for me to 'get at'?, and (2) If this something exists-is it possible for me to 'get at' it?

X. Hunt $(\bowtie)$

Department of Psychology, Faculty of Arts and Social Sciences, Stellenbosch University, Stellenbosch, South Africa

Institute for Life Course Health Research, Department of Global Health, Faculty of Medicine and Health Sciences, Stellenbosch University, Stellenbosch, South Africa

L. Swartz

Department of Psychology, Faculty of Arts and Social Sciences, Stellenbosch University, Stellenbosch, South Africa

e-mail: Lswartz@sun.ac.za

(C) The Author(s) 2021

X. Hunt et al. (eds.), Physical Disability and Sexuality, https://doi.org/10.1007/978-3-030-55567-2_8 
For instance, (1) Is there the right to vote? (yes), and (2) Am I as a woman allowed to vote? (yes) (1) Is there a dentist in my area? (yes), and (2) Does the dentist have enough capacity to serve a new client? (yes)

In these scenarios, I have access to the vote and access to dental care.

Now, the third layer: Is there some hard to define social, cultural, or otherwise not readily visible force which might stop me from 'getting at' the thing I can access (technically), according to layers one and two?

Will my dad let me leave the house for long enough to vote? Would the people at the voting booth turn me away, despite the legality of my desire to vote? Would the dentist turn me away because he does not serve tall people? Is his office in an area I cannot access because my car does not have four-wheel drive?

In these scenarios, I cannot cast my ballot, and my teeth remain uncared for. I do not, functionally, have access to voting rights or dental care.

For people with physical disabilities, any or all three of these layers of access might be compromised when it comes to a range of services and rights.

In this chapter, we are concerned with access to sexual and reproductive health $(\mathrm{SRH})$ services, but the reader should bear in mind that what goes for SRH goes for just about everything else; access is a substantial issue for people with physical disabilities (and people with disabilities more generally).

And even though this chapter is about SRH broadly, it is focussed on issues of access because, as we will see, access cuts across most SRH issues, and this is particularly the case for people with physical disabilities in South Africa.

So back to the layers.

For the first layer, our question in this chapter is this: are there SRH services for people with physical disabilities generally, and in South Africa in particular?

\footnotetext{
S. H. Braathen

Department of Health Research, SINTEF Digital, Oslo, Norway

e-mail: stine.h.braathen@sintef.no

P. Rohleder

Department of Psychosocial and Psychoanalytic Studies, University of Essex, Colchester, UK e-mail: p.rohleder@essex.ac.uk
} 
For the second layer, we want to know: is it possible for people with physical disabilities to access SRH services, and what did study participants say about this?

Finally, we want to know whether there are forces-social and cultural and otherwise not so visible stuff-which stop people with physical disabilities from accessing SRH services, and what does this look like in South Africa?

We are going to focus on SRH services here because they lie at the centre of SRH: it is hard to have sexual and reproductive health if we cannot access health services. The foregoing chapters in this book deal with the other facets of SRH and sexual life quite comprehensively, and so here we want to think about clinics and doctors and nurses, sex education classes, having or not having babies, and other health-related things.

We draw on data from interviews with participants from this project, as well as reviews of the literature. Because this project and the participants' narratives are situated in a South African and thus a southern perspective, we focus on the literature from low- and middle-income countries (LMICs).

Are there sexual and reproductive health services for people with physical disabilities?

In a 2009 guidance note for the World Health Organization, Groce et al. (UNFPA, 2009, p. 5) wrote,

All too often, the SRH of persons with disabilities has been overlooked by both the disability community and those working on SRH. This leaves persons with disabilities among the most marginalised groups when it comes to SRH services. Yet persons with disabilities have the same needs for SRH services as everyone else. In fact, persons with disabilities may actually have greater needs for SRH education and care than persons without disabilities due to their increased vulnerability to abuse.

Ten years after that document was published, there is still solid evidence that SRH services for people with disabilities, including people with physical disabilities, are scant (Ahumuza, Matovu, Ddamulira, \& Muhanguzi, 2014; DeBeaudrap et al., 2019; Iezzoni \& Mitra, 2017; Mosher et al., 2017; Ride \& Newton, 2018; Trani et al., 2011).

What we mean by 'SRH services for people with disabilities', is two things, and both are lacking. Firstly, there are few general health services in SRH which are accessible to people with disabilities. Secondly, there are few SRH services which are specifically targeted at serving people with disabilities. In both instances, this is particularly the case in LMICs 
like South Africa (Ahumuza et al., 2014; Smith, Murray, Yousafzai, \& Kasonka, 2004; Trani et al., 2011).

Recent studies show that sexual health problems are more prevalent among people with disabilities than among people without disability, and sexual dysfunctions, problems in intimate relationships, and practical difficulties in sexual activities are more prevalent among people with physical disabilities (Pieters, Kedde, \& Bender, 2018). Spinal cord injuries, for instance, can result in erectile dysfunctions, pain during sexual intercourse, reduced subjective arousal, and difficulties achieving orgasm (Pieters et al., 2018).

However, there is a substantial amount of evidence which shows that-when optimally supported by medical interventions, rehabilitation professionals, intimate partners, and others-people with physical disabilities can engage in meaningful and satisfying sexual lives (Ayaz et al., 2018; Hunt, Braathen, Swartz, Carew, \& Rohleder, 2018). Much of what makes this possible are adequate supportive services and accommodations.

There was very little support for people with disabilities; very little sexual health and reproductive support. I mean, there was little psychological support and very little support when it came to abilities to have sexual intercourse and all those things. So it was just like a...not a learning curve...but ja, whatever happens, happens.-Simon

As the above quote from a male participant highlights, for people with acquired physical disabilities, despite the importance of such assistance, there may be little support in the course of their rehabilitation, for SRH and sexual life. Upon acquiring a disability, and entering occupational therapy or other rehabilitative services, sexuality, and re-entry into sexual life as a person with a physical disability has historically been overlooked (Tepper, 1992). Recent research suggests that this is changing in highincome countries (HICs) to some degree (Pieters et al., 2018), but due to the general scarcity of services and overloading of those which do exist in LMICs, there are still failures in provision in South Africa (Rohleder et al., 2012; Wazakili, Mpofu, \& Devlieger, 2009).

For people with congenital disabilities, and people with acquired disabilities after the period of acute rehabilitation, the difficulties of accessing SRH services endure.

For the general population of South Africans (regardless of disability status), SRH service delivery is patchy. Data suggest that sexual education in the country is not uniformly delivered (Africa, 2019), HIV testing 
services are underutilised (Africa, 2019), and social, cultural, and attitudinal barriers exist, particularly for women trying to access SRH services. Nurses, for instance, have been found to treat young women poorly when the latter attempt to access contraception or prenatal care (Holt et al., 2012; Wood \& Jewkes, 2006).

There is very little data about whether or not people with physical disabilities are accessing general SRH services. In South Africa, for instance, the Department of Health keep no record of whether women giving birth at a government facility have a disability. This makes it hard to tell whether women with physical disabilities are having babies or not; if they are, whether they are having them at health facilities or not, and if they are not, why not?

One of the greatest learnings from the study on sexuality and disability has to do with the immense lack of epidemiological data about SRH for people with disabilities, and the SRH of people with disability.

There is also evidence that people with physical disabilities may require supports in SRH which make specialised services necessary (Pieters et al., 2018). As one of the participants noted:

As far as sexual health and reproductive clinics are concerned, I usually go once a year for bladder check-ups. But I don't really attend such clinics. There aren't really sex clinics to look at stuff. It's almost like sex is nonexistent for people with disabilities.-Vic

Given the overall lack of services in LMICs, there are almost no specialised SRH services for people with physical disabilities. Even in HICs, these are lacking. For instance, Mosher et al. (2017) found that American women with physical disabilities reported lower receipt of family planning services compared to women without disabilities. In their large survey in the United States, the authors found that discrepancies in access were larger among low-income women (Mosher et al., 2017). Similarly, in Canada, Tarasoff (2017) found that perinatal care systems are not set up to cater for women with physical disabilities. They noted that barriers to care might contribute to poor outcomes for women with disabilities and their infants.

In South Africa, task-shifting approaches, which utilise paraprofessional community health workers, have been successful in extending health services to hard to reach and underserved populations (Lewin et al., 
2010). However, as we will see in the following sections, unless attitudinal barriers to service provision for people with physical disabilities are removed, disparities in access will likely endure, even if the number of service provision options increases.

A final note which should be made in this section, regarding the existence of SRH services, has to do with sex education at schools. Sex education-any content delivered routinely in schools which concerns sexuality, sexual health, gender identity, and related thematic areasis largely overlooked at schools for people with physical disabilities. Although South Africa as a country has a standard sex education (so-called 'sex ed') curriculum, delivered as part of the subject Life Orientation, there is evidence that in schools for children with disabilities, this curriculum is poorly and inconsistently implemented (Chirawu, HanassHancock, Aderemi, de Reus, \& Henken, 2014). Moreover, it does not address disability-specific sex education, and as such may not be sufficient to meet the education needs of children with disabilities, including children with physical disabilities.

Given that the study participants were all already adults at the time that we conducted their interviews, there were few retrospective accounts of sex education. Further, given that these would have referred to a time often decades before the start of the study, it may not have been relevant here. However, one participant discussed her sexual development, and the disinclination of the adults in her world to engage in dialogue about sexuality. She noted:

When I became a young woman and I started getting my periods, my mum looked at me with big eyes, but she never told me what's happening here. I had to fend for myself. I had to learn this from school. Even at school they wouldn't say much: be careful of the boys, but nobody made it clear to me... I was never educated. Nobody spoke to me about sex. Nobody gave me the facts of life. I had to hear and pick it up as people spoke or from my surroundings or whatever. So whatever I gathered as I grew up, I had certain beliefs, although I wasn't even sure if it was factual.

Despite the fact that she was referring to an experience that happened in the 1980s, recent evidence from South African adolescents and young adults suggests that not much has changed since the participant's time (Chappell, 2016; Chirawu et al., 2014; de Reus, Hanass-Hancock, Henken, \& van Brakel, 2015). 
One of the concluding points concerning the existence of services, before we turn to a discussion of access, is that the lack of service provision for people with physical disabilities creates vulnerability and risk, over and above that already experienced by people with disabilities as a marginalised group. For instance, it has been suggested that women with physical disabilities' lack of social experience (due to parental or teacher attitudes) and lack of exposure to sexual education, creates additional vulnerability to sexual violence, and may lead women with physical disabilities to be less likely to disclose violence experiences (Crawford \& Ostrove, 2003; Kvam \& Braathen, 2008).

Lack of sexual health education has also been cited as a risk for unwanted pregnancy, the contraction of sexually transmitted diseases, and limited sexual expression among adolescents with disabilities (Bremer, Cockburn, \& Ruth, 2010; Nguyen, Liamputtong, \& Monfries, 2016; Seidel, Wienholz, Michel, Luppa, \& Riedel-Heller, 2014).

Is it possible for people with physical disabilities to access SRH services, and what did study participants say about this?

The next question, pertinent to our discussion of access, has to do with structural barriers people with physical disabilities encounter in going to clinics and hospitals and obtaining SRH services. If services which could serve the SRH needs of people with physical disabilities do exist, what practical things get in the way of this happening?

The first barrier worth noting is that buildings may be inaccessible and clinics and other SRH services unwelcoming to people with physical disabilities.

Studies examining access to health care for people with disabilities in South Africa have found a multitude of barriers to access, including inaccessibility of health facilities (lack of accessible toilets, ramps, etc.), problems getting to/from health facilities (lack of accessible transport, lack of support, etc.), lack of staff and equipment at facilities, geographical barriers (terrain, distance, crime, etc.), and attitudinal barriers (see for instance, Mji et al., 2017; Vergunst et al., 2017; Vergunst, Swartz, Mji, MacLachlan, \& Mannan, 2015). In the image below, one of our participants, Simon, illustrated what physical barriers could look like, and 'feel like', both practically, but also metaphorically.

As one of the participants explained:

It's quite a tricky situation seeing a person with a disability still going to ask for condoms. Some people don't feel comfortable in doing it. Most 
people with disabilities won't go to the hospital and ask for condoms. On the other hand, they won't have the financial capabilities of buying condoms as well, so they end up not using condoms.-Tas

Although Tas does not explicitly note why it is that people with [physical] disabilities do not go the clinic, he suggests that discomfort arises from providers' or members of the public's assumptions that people with physical disabilities do not need condoms (and as such should not be sexual in the first place).

Furthermore, service providers' lack of knowledge about disability produces a negative effect on accessibility. Vic explains that 'these health facilities, they know very little about people with disabilities and sex and sexual reproduction'.

Now, the right of people with disabilities to enjoy the highest attainable standard of health without discrimination is clearly stated in Article 25 of the United Nations Convention on the Rights of Persons with Disabilities (UNCRPD). This treaty was ratified by 175 countries in 2017 , including South Africa.

Yet, people with disabilities are up to four times more likely than people without disability to find health care providers' skills and facilities inadequate to meet their health needs (not to mention to be denied health care and to be treated poorly in contacts with the health care system) (Aresu, 2018). The information available on barriers and facilitators to health care for people with disabilities remain limited with little data disaggregated by region, gender, age, or disability (Aresu, 2018).

Furthermore, prior to the UNCRPD, at the United Nations General Assembly in 2015, the adoption of the Sustainable Development Goals (SDGs) included disability in the post-Millennium Development Goals definition, which set the ambitious goal of leaving 'no one behind'. SDG 3 seeks to ensure healthy lives and promote well-being for all at all ages.

Yet, WHO estimates that $50 \%$ of people with disabilities cannot afford health care, which brings into focus perhaps one of the most pervasive barriers to health care access for people with physical disabilities: lack of economic means.

People with disabilities are, on average, poorer than people without disabilities (Braithwaite \& Mont, 2009; Eide \& Ingstad, 2011; Groce, Kett, Lang, \& Trani, 2011). This is because employment opportunities which are accommodating of people with disabilities are fewer than for people without disability, and because the requirements for functional 
supports engendered by impairments (like needing a wheelchair, or accessible transport), can be substantial: so, a person with a physical disability may be less able to earn, and yet have expenses greater than, a person without disability.

As Nico explains, this has significant implications for sexuality and life quality:

I've got to use equipment or I have to use some medication to give me that stamina, that feeling back, that energy back, to be intimate with a partner. I mean, it's part of life. Sometimes, for example, I can't afford to get that specific treatment, then I'm stranded.

\section{He continued:}

I used to get the same treatment at the rehabilitation centre where you do physio here, but due to finance-wise they don't give it anymore. But now they will give you a prescription to a specific place, but in that case you have to pay more but you have to pay for your pleasure, plus-minus R500, just for that specific thing that you want. And if that specific thing is finished you just have to repeat again. It's a lot of money. That is the case we are busy with now. And in my instance also I had to order these things. You have to pay for the product and you have to pay for the delivery as well. So it's a kind of tricky situation there that I'm going through now. And at the end of the day, but that is what you want or that is what you need, not just for yourself but for your partner as well. Can you see what physically-challenged people have to go through on a daily basis.

Another participant, Simon, similarly noted:

I don't have support for assistive devices, all those things. Everything that I have and that I have to use, I pay out of my pocket. So, a lot of my finances go into just being able to operate affectively. I mean, my wheelchair costs R100 000. Where does that come from? It's my savings that went in there. The adaptations to my car, you know, proper cushions, looking after your health, all those things, it's a huge cost. I actually just work to provide for my disability at the moment, and that's tough.

What these participants' narratives point to is the impact of disability on an individual's economic situation, and the consequences of not being able to afford accommodations, on people's lives, and-in this studytheir sexual well-being.

What else gets in the way? 
It should be clear, from the above discussion, that even when there are services, and even when progress is made in provision, specifically for people with physical disabilities, when it comes to SRH information and services, the rights of this population continue to be violated.

It is clear, from a substantial body of research evidence, that much of this continued difficulty is due to deep-rooted discriminatory attitudes and practices from service providers and the public. What is more, even when attitudes are not explicitly discriminatory, the depth of societal assumptions about people with physical disabilities means that prejudicial behaviour is acted out by people without disability, even without the intention of doing so (Hunt et al., 2018).

Assumptions are part of the problem, here: as people with physical disabilities are taken to be asexual, the need for sex education for youth with physical disabilities is overlooked or improperly provided (Cheausuwantavee, 2002; East \& Orchard, 2014; Seidel et al., 2014). We noted above that provision of sex education for young people with physical disabilities is limited, but what is also clear is that the reason for this is often teachers' knowledge and attitudes. The misconception that people with physical disabilities are asexual and so sexually inactive means that education systems and educators may overlook the need for sex education for students with disabilities (Pebdani, Johnson, \& Amtmann, 2014).

As noted above, people with physical disabilities face additional risk of negative SRH outcomes, and sexual violence. Yet, despite this risk, two South African studies have produced evidence that educators tasked with delivering sex education content to students with disabilities lacked the knowledge and confidence to successfully teach this student population (Chirawu et al., 2014; de Reus et al., 2015). This again increased the students' vulnerability to HIV (de Reus et al., 2015; Wazakili et al., 2006).

Exacerbating the vulnerabilities created by the dearth of sexual health education, is the fact that almost nothing is known about how or if HIV prevention is being rolled out in South Africa for youth with disabilities (Chappell, 2016). This is despite the fact that researchers have noted an urgent need to provide sexuality education for youth with disabilities, and that HIV prevention is one of the primary public health foci of the country in relation to youth without disability (de Reus et al., 2015; Hunt et al., 2017).

The participants in the study discussed attitudinal barriers to access extensively. 
One participant, who was living with a congenital disability, recounted the horrific encounter which she had with a health care provider:

I went to a professor of genetics, and he was very cold. He said, well, if we had already found out the genes that cause [your condition], your abortion would be legalised. And I just remember reeling and then walking out of there thinking, that man thinks my life isn't worth living, that [my condition] is a reason for abortion. So the whole motivation why I went to ask him about this so that I could be better informed, was just like blanketed by that.-Anne

Meanwhile, Pride explained:

$\mathrm{Oh}$, the nurses [at the clinic] were also like, why? What are you doing here? I came for prevention. And then? Why? Do you have a boyfriend? Yes, nurse, I have a boyfriend. No, this is not right.

Interviewer: Because of your disability?

Participant: Yes, how can you have a boyfriend? You can't have a boyfriend if you have a disability.

Pride, and other participants, explained that service providers found their requests - as people with physical disabilities-for HIV tests, contraception, or pregnancy services, strange or surprising, evidencing an underlying assumption that physical disability rendered people unfit for, or not in need of, SRH services.

\section{CONCLUding NOTES AND TAKE-HOME POINTS}

Clearly, people with physical disabilities are excluded from sexual health education (Cheausuwantavee, 2002; Seidel et al., 2014), and sexual and reproductive health care (Hunt et al., 2017; Peta, 2017). They also experience challenges to their sexual development and assaults on their sexual self-esteem by people without disability who assume that they are less sexual because of their disability (Hunt, 2018). People with physical disabilities are also, often, lacking in access to sexual education (de Reus et al., 2015), and this might lead to additional SRH vulnerabilities, particularly in South Africa.

When a phenomenon, like access to SRH for people with physical disabilities, is determined by so many things it may seem hard to propose 
solutions. What thinking about access in terms of layers, as laid out here, might help us to do is find targeted solutions for every determinant.

Let's revisit our framework:

For the first layer: how can we increase the number of SRH services for people with physical disabilities in South Africa?

For the second layer: how can we make SRH services more accessible to people with physical disabilities?

Finally: how can we shift the societal norms, assumptions, and prejudices which get in the way of people with physical disabilities accessing of SRH services?

Coverage and knowledge of what is needed-Clearly, SRH service coverage in South Africa needs to be widened and in a more equitable way, for all people. However, it is also apparent that specialised services for people with physical disabilities are needed. Specialist service provision needs to be grounded in the evidence base, and so what is required, first and foremost, is service-user research into the kinds of accessible services which might be most useful for people with physical disabilities in accessing SRH services. Epidemiological data, too, are needed if we are to have a better position from which to lobby for specialised services: as long as the scope of the need goes undefined, it will be hard to motivate for service delivery in an already over-burdened system.

Accessibility-Those environments, products, or services which cater for SRH in South Africa must be able to meet the needs of all persons, including people with physical disabilities (Aresu, 2018).

Participation-Efforts to improve SRH services must include the meaningful engagement of women and men, boys and girls living with physical disabilities in the design, implementation, monitoring, evaluation of all programmes, and policies affecting their lives (Aresu, 2018).

Equality and non-discrimination-Finally there needs to be widespread, systematic actions to challenge all of the attitudes, behaviours, and policies which discriminate against people on the grounds of disability (Aresu, 2018). Particular efforts need to be focussed on shifting public and service provider attitudes to the sexuality of people with physical disabilities, as these have a clear, deleterious impact on the SRH of people with physical disabilities. 


\section{REFERENCES}

Africa, D. W. B. M. S. (2019). Doctors without borders: Lack of SRH services in schools, leaves teenagers vulnerable to the risk of HIV infections. Retrieved from https://albertonrecord.co.za/200663/doctors-without-bor ders-lack-srh-services-schools-leaves-teenagers-vulnerable-risk-hiv-infections/.

Ahumuza, S. E., Matovu, J. K., Ddamulira, J. B., \& Muhanguzi, F. K. (2014). Challenges in accessing sexual and reproductive health services by people with physical disabilities in Kampala, Uganda. Reproductive Health, 11(1), 59. https://doi.org/10.1186/1742-4755-11-59.

Aresu, A. (2018). Disability-inclusive health is essential to achieving UHC. Retrieved from https://womendeliver.org/2018/promote-disability-inclus ive-health-is-essential-to-achieve-uhc/.

Ayaz, S. B., Qureshi, A. R., Ahmad, A., Gill, Z. A., Ahmad, N., \& Butt, A. W. (2018). Sexual functioning in a cohort of Pakistani men with spinal cord injury. Sexuality and Disability, 36(4), 377-388.

Braithwaite, J., \& Mont, D. (2009). Disability and poverty: A survey of world bank poverty assessments and implications. ALTER-European Journal of Disability Research/Revue Européenne de Recherche Sur Le Handicap, 3(3), 219-232.

Bremer, K., Cockburn, L., \& Ruth, A. (2010). Reproductive health experiences among women with physical disabilities in the Northwest region of Cameroon. International Journal of Gynecology o Obstetrics, 108(3), 211-213.

Chappell, P. (2016). Secret languages of sex: Disabled youth's experiences of sexual and HIV communication with their parents/caregivers in KwaZuluNatal. South Africa. Sex Education, 16(4), 405-417.

Cheausuwantavee, T. (2002). Sexual problems and attitudes toward the sexuality of persons with and without disabilities in Thailand. Sexuality and Disability, 20(2), 125-134.

Chirawu, P., Hanass-Hancock, J., Aderemi, T. J., de Reus, L., \& Henken, A. S. (2014). Protect or enable? Teachers' beliefs and practices regarding provision of sexuality education to learners with disability in KwaZulu-Natal. South Africa. Sexuality and Disability, 32(3), 259-277.

Crawford, D., \& Ostrove, J. M. (2003). Representations of disability and the interpersonal relationships of women with disabilities. Women o Therapy, 26(3-4), 179-194.

DeBeaudrap, P., Mouté, C., Pasquier, E., Mac-Seing, M., Mukangwije, P. U., \& Beninguisse, G. (2019). Disability and access to sexual and reproductive 
health services in Cameroon: A mediation analysis of the role of socioeconomic factors. International Journal of Environmental Research and Public Health, 16(3), 417. https://doi.org/10.3390/ijerphl6030417.

de Reus, L., Hanass-Hancock, J., Henken, S., \& van Brakel, W. (2015). Challenges in providing HIV and sexuality education to learners with disabilities in South Africa: The voice of educators. Sex Education, 15(4), 333-347.

East, L. J., \& Orchard, T. R. (2014). Somebody else's job: Experiences of sex education among health professionals, parents and adolescents with physical disabilities in southwestern Ontario. Sexuality and Disability, 32(3), 335-350.

Eide, A. H., \& Ingstad, B. (2011). Disability and poverty: A global challenge. Bristol: Policy Press.

Groce, N., Kett, M., Lang, R., \& Trani, J.-F. (2011). Disability and poverty: The need for a more nuanced understanding of implications for development policy and practice. Third World Quarterly, 32(8), 1493-1513.

Holt, K., Lince, N., Hargey, A., Struthers, H., Nkala, B., McIntyre, J., ... Blanchard, K. (2012). Assessment of service availability and health care workers' opinions about young women's sexual and reproductive health in Soweto, South Africa. African Journal of Reproductive Health, 16(2), 283-294.

Hunt, X. (2018). Through a different lens: Examining commonality and divergence in constructions and depictions of the sexuality of persons with physical disabilities in South Africa.

Hunt, X., Braathen, S. H., Swartz, L., Carew, M. T., \& Rohleder, P. (2018). Intimacy, intercourse and adjustments: Experiences of sexual life of a group of people with physical disabilities in South Africa. Journal of Health Psychology, 23(2), 289-305.

Hunt, X., Carew, M. T., Braathen, S. H., Swartz, L., Chiwaula, M., \& Rohleder, P. (2017). The sexual and reproductive rights and benefit derived from sexual and reproductive health services of people with physical disabilities in South Africa: Beliefs of non-disabled people. Reproductive Health Matters, 25(50), 66-79.

Hunt, X., Swartz, L., Carew, M. T., Braathen, S. H., Chiwaula, M., \& Rohleder, P. (2018). Dating persons with physical disabilities: The perceptions of South Africans without disabilities. Culture, Health \& Sexuality, 20(2), 141-155.

Iezzoni, L. I., \& Mitra, M. (2017). Transcending the counter-normative: Sexual and reproductive health and persons with disability. Disability and Health Journal, 10(3), 369-370.

Kvam, M. H., \& Braathen, S. H. (2008). "I thought...maybe this is my chance": Sexual abuse against girls and women with disabilities in Malawi. Sexual Abuse, 20(1), 5-24.

Lewin, S., Munabi-Babigumira, S., Glenton, C., Daniels, K., Bosch-Capblanch, X., van Wyk, B. E., ... Zwarenstein, M. (2010). Lay health workers in primary 
and community health care for maternal and child health and the management of infectious diseases. Cochrane Database of Systematic Reviews (3): CD004015. https://doi.org/10.1002/14651858.CD004015.pub3.

Mji, G., Braathen, S. H., Vergunst, R., Scheffler, E., Kritzinger, J., Mannan, H., ... Visagie, S. (2017). Exploring the interaction of activity limitations with context, systems, community and personal factors in accessing public health care services: A presentation of South African case studies. African Journal of Primary Health Care \& Family Medicine, 9(1), 1-9.

Mosher, W., Bloom, T., Hughes, R., Horton, L., Mojtabai, R., \& Alhusen, J. L. (2017). Disparities in receipt of family planning services by disability status: New estimates from the national survey of family growth. Disability and Health Journal, 10(3), 394-399.

Nguyen, T. T. A., Liamputtong, P., \& Monfries, M. (2016). Reproductive and sexual health of people with physical disabilities: A metasynthesis. Sexuality and Disability, 34(1), 3-26.

Pebdani, R. N., Johnson, K. L., \& Amtmann, D. (2014). Personal experiences of pregnancy and fertility in individuals with spinal cord injury. Sexuality and Disability, 32(1), 65-74.

Peta, C. (2017). Disability is not asexuality: The childbearing experiences and aspirations of women with disability in Zimbabwe. Reproductive Health Matters, 25(50), 10-19.

Pieters, R., Kedde, H., \& Bender, J. (2018). Training rehabilitation teams in sexual health care: A description and evaluation of a multidisciplinary intervention. Disability and Rebabilitation, 40(6), 732-739.

Ride, G., \& Newton, D. C. (2018). Exploring professionals' perceptions of the barriers and enablers to young people with physical disabilities accessing sexual and reproductive health services in Australia. Sexual Health, 15(4), 312-317.

Rohleder, P., Eide, A. H., Swartz, L., Ranchod, C., Schneider, M., \& Schür, C. (2012). Gender differences in HIV knowledge and unsafe sexual behaviours among disabled people in South Africa. Disability and Rehabilitation, 34(7), 605-610.

Seidel, A., Wienholz, S., Michel, M., Luppa, M., \& Riedel-Heller, S. G. (2014). Sexual knowledge among adolescents with physical handicaps: A systematic review. Sexuality and Disability, 32(3), 429-441.

Smith, E., Murray, S., Yousafzai, A., \& Kasonka, L. (2004). Barriers to accessing safe motherhood and reproductive health services: The situation of women with disabilities in Lusaka. Zambia. Disability and Rebabilitation, 26(2), 121127.

Tarasoff, L. A. (2017). “We don't know. We've never had anybody like you before": Barriers to perinatal care for women with physical disabilities. Disability and Health Journal, 10(3), 426-433. 
Tepper, M. S. (1992). Sexual education in spinal cord injury rehabilitation: Current trends and recommendations. Sexuality and Disability, 10(1), 15-31. Trani, J.-F., Browne, J., Kett, M., Bah, O., Morlai, T., Bailey, N., \& Groce, N. (2011). Access to health care, reproductive health and disability: A large scale survey in Sierra Leone. Social Science os Medicine, 73(10), 1477-1489.

UNFPA. (2009). Promoting sexual and reproductive health for persons with disabilities. Retrieved from https://www.unfpa.org/sites/default/files/pubpdf/srh_for_disabilities.pdf.

Vergunst, R., Swartz, L., Mji, G., MacLachlan, M., \& Mannan, H. (2015). 'You must carry your wheelchair'-barriers to accessing health care in a South African rural area. Global Health Action, 8, 29003. https://doi.org/ 10.3402/gha.v8.29003.

Vergunst, R., Swartz, L., Hem, K.-G., Eide, A. H., Mannan, H., MacLachlan, M., Mji, G., Braathen, S. H., \& Schneider, M. (2017). Access to health care for persons with disabilities in rural South Africa. BMC Health Services Research, 17, 741. https://doi.org/10.1186/s12913-017-2674-5.

Wazakili, M., Mpofu, R., \& Devlieger, P. (2006). Experiences and perceptions of sexuality and HIV/AIDS among young people with physical disabilities in a South African township: A Case study. Sexuality and Disability, 24(2), 77.

Wazakili, M., Mpofu, R., \& Devlieger, P. (2009). Should issues of sexuality and HIV and AIDS be a rehabilitation concern? The voices of young South Africans with physical disabilities. Disability and Rehabilitation, 31(1), 32-41.

Wood, K., \& Jewkes, R. (2006). Blood blockages and scolding nurses: Barriers to adolescent contraceptive use in South Africa. Reproductive Health Matters, 14(27), 109-118.

Open Access This chapter is licensed under the terms of the Creative Commons Attribution 4.0 International License (http://creativecommons.org/licenses/ by $/ 4.0 /)$, which permits use, sharing, adaptation, distribution and reproduction in any medium or format, as long as you give appropriate credit to the original author(s) and the source, provide a link to the Creative Commons license and indicate if changes were made.

The images or other third party material in this chapter are included in the chapter's Creative Commons license, unless indicated otherwise in a credit line to the material. If material is not included in the chapter's Creative Commons license and your intended use is not permitted by statutory regulation or exceeds the permitted use, you will need to obtain permission directly from the copyright holder.

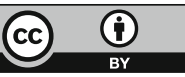

